\title{
Sobre (r)existências e ações cole (a)tivas na triste era do bolsonarismo
}

DOI

http://dx.doi.org/10.11606/ 2179-0892.ra.2020.180166
Laura Moutinho

Universidade de São Paulo | Faculdade de Filosofia, Letras e Ciências

Humanas | Departamento de Antropologia| São Paulo, SP, Brasil |

Imoutinho@usp.br|https://orcid.org/0000-0001-6479-2711

\author{
Pedro de Niemeyer Cesarino \\ Universidade de São Paulo | Faculdade de Filosofia, Letras e Ciências \\ Humanas | Departamento de Antropologia São Paulo, SP, Brasil | \\ pedrocesarino@gmail.com | https://orcid.org/0000-0002-4158-7712
}

Sylvia Caiuby Novaes

Universidade de São Paulo | Faculdade de Filosofia, Letras e Ciências

Humanas | Departamento de Antropologia | São Paulo, SP, Brasil |

scaiuby@usp.br|https://orcid.org/0000-0002-7415-2010

Oposição não é o bastante. No espaço deixado por aquele que resiste ainda há a necessidade do devir - da renovação de si mesmo.

bell hooks

No momento de escrita deste editorial o Brasil caminha a passos largos para o tão astronômico como trágico número de 200.000 mortes por Covid-19. São quase 200.000 pessoas mortas, que deixam um rastro de dor, sofrimento e luto difícil de ser vivido na sua real dimensão diante da ausência de rituais funerários, que são impossíveis de serem seguidos em função das restrições sanitárias.

Caixões lacrados e velórios de poucos minutos convivem, como sabe a população brasileira, com a política histriônica da presidência da República e com o descaso e a falta de empatia de todo o governo federal com quem sofre. Concomitante às mortes, o Brasil enfrenta uma política de extrema direita de orientação neoliberal que, com ares fascistas, explicitamente anseia e age no sentido de eliminar as diferenças e o pensamento divergente. A arrogância (e não a compaixão) invade os lares das pessoas que estão lutando pela vida ou em luto.

O trágico momento que vivemos é reiterado diariamente por assassinatos (ou seriam linchamentos?), como o que testemunhamos pelas imagens aterrorizantes da violenta morte de João Alberto Silveira Freitas, o Beto, assassinado por dois seguranças em uma loja da rede de supermercados Carrefour, na frente de sua esposa e de câmeras de celular, aos 40 anos de idade. Os corpos ganharam uma materialidade espessa nesses meses em que nos vemos imersos na pandemia da Covid-19 e na espetacularização da morte violenta de pessoas negras. O sentimento de perda é hoje uma constante para todes. Ameaças à democracia, sofrimento, luto e formas de governança vêm sendo debatidos cotidianamente. 
Ainda que em declínio no momento, são muitos os que aderiram a um discurso conservador, que se constrói a partir de um populismo digital (Letícia Cesarino, 2019), que autoriza a discriminação, a arrogância, mobilizando teorias conspiratórias e discursos de ódio. Um olhar para o cotidiano dessa dinâmica política evidencia que a categoria sofrimento é central nesse debate e não apenas para a massa de pessoas que se sente vulnerável face aos ataques constantes, tanto aos direitos constitucionais quanto a tudo que representa a linguagem dos direitos humanos (Laura Moutinho, Heloisa Almeida \& Júlio Simões, 2020). De fato, paradoxalmente, chama atenção o peso dos eleitores da periferia na eleição de Jair Bolsonaro e a forma como toda uma gramática moral agencia subjetividades políticas (Charles Klein; Milena Carmo \& Alessandra Tavares, 2020).

Nessas escalas sobrepostas de experiências, testemunhamos ações de "(r)existências e cole(a)tivas", como nos convoca a pensar Lea Tosold (2020) em artigo publicado nesse número. Escritas feitas com os sentidos (Marília Pisani, 2020), esses mesmos que estão aguçados como nunca neste momento da pandemia, vêm permeando não somente as experiências mais subjetivas, mas igualmente reações às políticas instituídas.

Black Lives Matter mostra a força de um movimento antirracista, que se espraia em instâncias jamais vistas no Brasil, confrontando tanto o racismo cotidiano, quanto o institucional e o corporativo. O movimento decolonial bate à porta da produção acadêmica questionando, como o fez Zethu Matebeni (2017)', sobre o que o conhecimento produzido nesse contexto tem retribuído a todes que têm emprestado suas vidas informando estudos contemporâneos e plataformas político-acadêmicas.

Abre este número, o último de 2020, o artigo de Lea Tosold, intitulado "Por uma vida sem barragens: corpos, território e o papel da autodeterminação na desnaturalização da violência", ao qual também se refere a foto de capa. A bela fotografia, de autoria de Nayana Fernández, foi realizada na Aldeia Munduruku de Sai Cinza, Jacareacanga, Pará, em 2015. Toda a escolha foi cuidadosa: a autora trabalhou como Coletivo Comtapajós e a foto foi enviada para Kabaiwun Munduruku para seu consentimento. A Revista de Antropologia presta aqui seu apoio à luta Munduruku, cuja força fica evidente no artigo. O texto aborda o processo de resistência do povo Munduruku à tentativa de construção das barragens de São Luiz e Jatobá, na bacia do rio Tapajós, entre 2013 e 2015. A autodeterminação evidencia a violência do que se chama de progresso e concomitantemente abre um conjunto de possibilidades de ação, mesmo numa desigual correlação de forças. Os limites das normativas legais aparecem nesse movimento.

Os impedimentos coloniais e racistas são analisados por Antonádia Borges (2020) no artigo "Very rural background: os desafios da composição-terra da África do Sul e do Zimbábue à chamada educação superior". Ao abordar o ensino universitário, a autora mostra como uma composição-plantation, um processo de aniquilamento colonial e racista, evidencia sua força na forma como transforma o humano em human resource na universidade.
1 Para conhecer mais a reflexão da autora, ver também a conferência proferida na $32^{\mathrm{a}}$ Reunião da Associação Brasileira de Antropologia "Unongayindoda: fazendo o gênero em um contexto sul-africano" (disponível em https://www.youtube.com/ watch?v=ImmMMEzC]yk) e a entrevista publicada na Revista de Antropologia realizada por Thais Tiriba e Laura Moutinho (2017). 
A Educação Superior continua como tema no artigo "Eu escrevo o quê, professor (a)?': notas sobre os sentidos da classificação racial (auto e hetero) em políticas de ações afirmativas", de Ana Paula Mendes de Miranda, Rolf Ribeiro de Souza \& Rosiane Rodrigues de Almeida (2020). Rumores e suspeição, categorias centrais do argumento de Tosold (2020), anteriormente mencionado, retornam na análise da regulamentação das cotas raciais na forma como isso aparece nas comissões de hétero-identificação.

A questão identitária e o reconhecimento de formas culturais subalternizadas ecoam os artigos anteriores na análise de Livio Sansone (2020), em artigo intitulado "O sucesso e a crise da onda identitária no Brasil". Multiculturalismo e ações afirmativas são analisados na correlação com a onda conservadora que os colocam em xeque.

Também referente às transformações mundiais das políticas de identidade e de nacionalismo, Fabiano Contijo (2020) explora as consequências do processo revolucionário ucraniano em "Nação, simbolismo e revolução na Ucrânia: experiência etnográfica tensa na/da liminaridade", compreendidas através da produção de uma nova ideologia de "nation building" em sua separação de vínculos históricos com a Rússia.

Ana Lúcia Pastore Schritzmeyer (2020), por sua vez, analisa um outro aspecto provavelmente associado ao recrudescimento do conservadorismo no Brasil. "Na dúvida, foi moralmente condenada ao invés de legalmente absolvida" apresenta um estudo etnográfico sobre o impacto de marcadores sociais e sua relação com o punitivismo nos julgamentos do Tribunal do Júri em São Paulo.

Ciméa Bevilacqua (2020), em "Burocracia, criatividade e discernimento: lições de uma cafeteira desaparecida", persegue os trâmites burocráticos envolvidos no sumiço de uma cafeteira em um órgão público federal, apontando para o esquematismo e a autonomia de processos conduzidos por atores do serviço público. O Estado aparece aqui mostrando sua face coletiva.

João Roberto Bort Junior e Fernanda Borges Henrique (2020), em "'Cada um em seu lugar': domínios territoriais Xucuru-Kariri e Kiriri", estudam os conflitos entre caciques xucuru-kariri e kiriri a partir de uma perspectiva cosmopolítica, na tentativa de mostrar como os processos de domínio territorial extrapolam as relações com o Estado, determinantes, de toda forma, em todos os demais artigos contemplados no presente número da Revista de Antropologia.

Marcel Mano (2020), no artigo "Guerras e saques: apropriações e incorporações diferenciais das alteridades entre os ]ê - 'Cayapó' meridionais", parece, em seu turno, complementar as análises de Lea Tosold sobre os Munduruku através de uma perspectiva histórica, desta vez dirigida ao estudo das guerras de saque entre os ]ê Caiapó meridionais, compreendidas como uma perspectiva simbólica para a relação com a alteridade e suas potenciais implicações políticas.

"Ser ou não ser pescadora artesanal? Trabalho feminino, reconhecimento e representação social entre marisqueiras da Bacia de Campos, R]", de Lilian Sagio Cezar 
(2020), apresenta uma reflexão sobre as desigualdades relacionadas à invisibilização das mulheres trabalhadoras envolvidas no Grupo Gestor da Pesca Artesanal.

Annelise Caetano Fraga Fernandez, Silvia Regina Nunes Baptista e Rafaela Paula da Silva (2020), em "Bananas para vender e histórias para contar: cultura alimentar local e identidades territoriais a partir de mercados orgânicos e agroecológicos", analisam as disputas de sentido envolvidas na produção de banana na região do Maciço da Pedra Branca, Rio de Janeiro, e as tensões sociais daí decorrentes.

Luiz Gustavo Mendel de Souza (2020), em "Devoção e resistência: as táticas dos anfitriões da Folia de Reis na região metropolitana do Estado do Rio de Janeiro", dá sequência ao conjunto de artigos relacionados à etnografia de situações sociais do Rio de Janeiro reunidos neste número, ao tratar, em diálogo com Michel de Certeau, das táticas envolvidas no circuito ritual dos devotos.

Michael Taussig é entrevistado por Carolina Parreiras (2020) em "Entre a prática, a teoria, a escrita e a experimentação etnográficas". A entrevista foi lançada junto à conferência do professor da Columbia University proferida na $32^{\mathrm{a}}$ Reunião da Associação Brasileira de Antropologia - Saberes insubmissos, diferenças e direitos. Quem se dedica a acompanhar os artigos da Revista de Antropologia poderá também assistir à conferência de Taussig na TV ABA².

Na seção Críticas Bibliográficas e Resenhas, Edwin B. Reesink (2020) apresenta o texto "Os donos dos parentes: sobre a assimetria sociopolítica Kanamari", uma resenha de The Owners of Kinship. Asymmetrical Relations in Indigenous Amazonia, de Luiz Costa.
Em 2020, a Revista de Antropologia completou 67 anos. Foi também ao longo deste ano que iniciamos a publicação continuada e bilíngue (português/inglês) da Revista, que agora também disponibiliza artigos na versãoXML. Com presença no Instagram, Twitter, Facebook e outras redes sociais, o periódico mais antigo da área de antropologia também poderá ser visualizado na plataforma SciELO. Num momento de ataques ao conhecimento científico, entendemos ser necessária essa ampliação da comunicação científica e do contato tanto com a comunidade acadêmica quanto com a sociedade mais ampla.

Além disso, uma nova comissão editorial assumiu o periódico em novembro deste ano. A editoria-chefe foi passada de Laura Moutinho para Pedro Cesarino. Sylvia Caiuby Novaes cede lugar a Heloisa Buarque de Almeida e Renato Sztuman, que já atuaram como editores-responsáveis e retornam, agora, na comissão editorial, que foi ampliada para dar conta do grande fluxo de artigos e várias outras demandas do mercado editorial dos periódicos científicos. São tempos de trabalhos coletivos e solidariedade. A Revista de Antropologia seguirá nesse diapasão, conectada com seu tempo.
2 | A conferência "Tom, $\mathrm{O}$ Naturalista" está disponível em: https://www.youtube.com/ watch?v=KvuqFCwe4bI\&ab_ channel=TVABA 
Laura Moutinho é professora Associada (Livre-Docente) do Departamento de Antropologia e do PPCAS ambos da USP. Foi editora-chefe da Revista de Antropologia até outubro de 2020. Coordena a Comissão Projeto Editorial da ABA. Publicou o livro Razão, Core Desejo: uma análise dos relacionamentos afetivo-sexuais inter-raciais no Brasile África do Sul, Editora Unesp: São Paulo, 2004, graças ao prêmio EDUSC\ANPOCS para melhor tese de doutoradoledição 2003. É bolsista a produtividade nível $1 \mathrm{D}$ do CNPq e tem apoio da FAPESP.

Pedro de Niemeyer Cesarino é professor do Departamento de Antropologia da FFLCH/USP, membro da comissão editorial da Revista de Antropologia e do Centro de Estudos Ameríndios (CESTA/USP). Especialista em etnologia indígena e nas relações entre antropologia, arte e literatura, publicou diversos artigos e livros, entre os quais Oniska - poética do xamanismo na Amazônia (Ed. Perspectiva, 2011) e Quando a Terra deixou de falar - cantos da mitologia marubo (Ed. 34, 2013).

Sylvia Caiuby Novaes é antropóloga, Professora Titular no Departamento de Antropologia da Universidade de São Paulo. Fundou, em 1991, o Laboratório de Imageme Som em Antropologia-LISA-USP, do qual éCoordenadora. Tem publicações na área de etnologia e imagem, e realizou filmes e ensaios fotográficos numa perspectiva antropológica. É membro da Comissão Editorial da Revista de Antropologia e do CEstA - Centro de Estudos Ameríndios. Bolsista do CNPq - PQ-1 e da FAPESP.

CONTRIBUiçõES DE AUTORIA: O texto foi escrito de modo colaborativo.

\section{REFERÊNCIAS BIBLIOCRÁFICAS}

BEVILAQUA, Ciméa Barbato. 2020. "Burocracia, criatividade e discernimento: lições de uma cafeteira desaparecida". Revista de Antropologia, 63(3): e178843. https://doi. org/10.11606/1678-9857.ra.2020.178843.

BORGES, Antonádia. 2020. "Very rural background: os desafios da composiçãoterra da África do Sul e do Zimbábue à chamada educação superior". Revista de Antropologia, 63(3): e178183. https://doi. org/10.11606/1678-9857.ra.2020.178183.
BORT JÚNIOR, João Roberto; HENRIQUE, Fernanda Borges. 2020. 'Cada um em seu lugar'. Domínios territoriais Xucuru-Kariri e Kiriri”. Revista de Antropologia , 63(3): e178845. http:// dx.doi.org/10.11606/1678-9857.ra.2020.178845.

CESARINO, Letícia. 2019. "Identidade e representação no bolsonarismo: Corpo digital do rei, bivalência conservadorismoneoliberalismo e pessoa fractal". Revista de Antropologia, 62(3): 530-557. https://doi. org/10.11606/2179-0892.ra.2019.165232. 
CEZAR, Lilian Sagio; THEIS, Rafaella. 2020. "Ser ou não ser pescadora artesanal? Trabalho feminino, reconhecimento e representação social entre marisqueiras da Bacia de Campos, R]". Revista de Antropologia, 63(3): e178848. http://dx.doi. org/10.11606/2179-0892.ra.2020.178848.

FERNANDEZ, Annelise Caetano Fraga: BAPTISTA, Silvia Regina Nunes; SILVA, Rafaela Paula da. (2020). "Bananas para vender e histórias para contar: cultura alimentar local e identidades territoriais a partir de mercados orgânicos e agroecológicos". Revista de Antropologia, 63(3): e178185. https://doi. org/10.11606/1678-9857.ra.2020.178185.

KLEIN, Charles; CARMO, Milena Mateuzi; TAVARES, Alessandra. 2020. "Between 'us' and 'them': political subjectivities in the shadows of the 2018 brazilian election". Revista de Antropologia, 63(2): e160722. https://doi. org/10.11606/2179-0892.ra.2020.171482.

MANO, Marcel. 2020. "Guerras e saques: apropriações e incorporações diferenciais das alteridades entre os ]ê- 'Cayapó' meridionais". Revista de antropologia 63(3): e178850. http://dx.doi. org/10.11606/2179-0892.ra.2020.178850.

MATEBENI, Zethu. 2017. "Perspectivas do Sul sobre relações de gênero e sexualidades: uma intervenção queer". Revista de Antropologia, 60(3): 26-44. https:// doi.org/10.11606/2179-0892.ra.2017.141826.

MIRANDA, Ana Paula Mendes de; SOUZA, Rolf Ribeiro de; ALMEIDA, Rosiane Rodrigues de. 2020. "Eu escrevo o quê, professor (a)?: notas sobre os sentidos da classificação racial (auto e hetero) em políticas de ações afirmativas". Revista de Antropologia, 63(3): e178854. http://dx.doi. org/10.11606/2179-0892.ra.2020.178854.
MOUTINHO, Laura; ALMEIDA, Heloisa Buarque; SIMÕES, Júlio Assis. 2020. "Grammars of damage and suffering in Brazil today". Vibrant: Virtual Brazilian Anthropology, 17: e17453. https://doi.org/10.1590/1809-43412020v17d453.

PARREIRAS, Carolina. 2020. "Entre a prática, a teoria, a escrita e a experimentação etnográficas: Entrevista com Michael Taussig". Revista de Antropologia, 63(3): 177099. https:// doi.org/10.11606/1678-9857.ra.2020.177099.

PISANI, Marília Mello. 2020. "Quando a filosofia se torna semente: viagem através de mundo artefactuais e (im)prováveis encontros". Revista Ideação, 42(1): 197-232. http://dx.doi.org/10.13102/ideac.v1i42.5479.

REESINK, Edwin B. 2020. "Os donos dos parentes: sobre a assimetria sociopolítica Kanamari". Revista de Antropologia, 63(3): e178858. https://doi. org/10.11606/1678-9857.ra.2020.178858.

SCHRITZMEYER, Ana Lúcia Pastore. 2020. "Na dúvida, foi moralmente condenada ao invés de legalmente absolvida: etnografia de um julgamento pelo Tribunal do Júri de São Paulo, Brasil". Revista de Antropologia, 63(3): e178180. https://doi. org/10.11606/1678-9857.ra.2020.178180.

SOUZA, Luiz Gustavo Mendel. 2020. “Devoção e resistência: as táticas dos anfitriões da Folia de Reis na região metropolitana do Estado do Rio de Janeiro". Revista de Antropologia, 63(3): e178857. http://dx.doi. org/10.11606/2179-0892.ra.2020.178857.

TIRIBA, Thais; MOUTINHO, Laura. 2017. "Olhares compartilhados': (des)continuidades, interseccionalidade e desafios da relação Sul-Sul. Entrevista com Zethu Matebeni". Revista de Antropologia, 60(3): 181-185. https:// doi.org/10.11606/2179-0892.ra.2017.141743. 
EDITORIAL | Laura Moutinho, Pedro de Niemeyer Cesarino e Sylvia Caiuby Novaes

| Sobre (r)existências e ações cole (a)tivas na triste era do bolsonarismo

TOSOLD, Léa. 2020. “Por uma vida sem barragens: corpos, território e o papel da autodeterminação na desnaturalização da violência". Revista de Antropologia, 63(3): e178182. https://doi. org/10.11606/1678-9857.ra.2020.178182. 